This is an author produced version of a paper published in BJOG : an international journal of obstetrics and gynaecology. This paper has been peer-reviewed but does not include the final publisher proof-corrections or journal pagination.

Citation for the published paper:

Karlsson, Magnus K and Ahlborg, Henrik G and Karlsson, Caroline

"Female reproductive history and the skeleton-a review."

BJOG. 2005 Jul;112(7):851-6

http://dx.doi.org/10.1111/j.1471-0528.2005.00571.x

Access to the published version may require journal subscription.

Published with permission from: Blackwell Synergy 


\title{
Female Reproductive
}

\section{History and The Skeleton}

\section{- A Review}

by

\author{
Magnus K. Karlsson, Henrik G. Ahlborg, Caroline Karlsson \\ Department of Orthopaedics, Malmo University Hospital, \\ SE -205 02, Malmo, Sweden
}

\section{Headline}

Increased bone loss follows a pregnancy and lactation but multiparous women have similar or lower fracture risk than nulliparous women

Correspondence: Magnus Karlsson, MD., Department of Orthopaedics, Malmo University Hospital, SE - 20502 Malmo, Sweden. Tel + 4640 333843, Fax + 4640336200 E-mail: magnus.karlsson@orto.mas.lu.se 


\section{Abstract}

Objective: Evaluate changes in bone mineral density (BMD) during pregnancy and lactation and evaluate BMD and fracture risk in nulli- and multiparous women.

Design: Review article

Setting: Manuscript published in PubMed from 1966.

Main outcome measure: Rate of BMD changes during pregnancy and lactation and BMD and fracture incidence in nulli- and multiparous women.

Results: Both a pregnancy and six month lactation was associated with an BMD loss of up to $5 \%$. In spite of this, women with many children and a long total period of lactation similar or higher BMD and similar or lower fracture incidence compared to their peers who have not given birth

Conclusions: The BMD loss found to be associated with a pregnancy and lactation must be regarded as a finding without clinical relevance, as multiparous women have similar or lower fracture risk than nulliparous women. 


\section{Introduction}

Bone mineral density (BMD) is generally regarded as the best predictor of bone strength, and one standard deviation decrease in BMD (around 10\%) is known to double the fracture risk (1). If BMD reaches a value of 1.0-2.5 SD lower than young individuals of the same gender, we call the condition osteopenia, and if the BMD ends up 2.5 SD lower, we call it osteoporosis (2). This is a condition to avoid, as with the increasing prevalence of osteoporosis, more and more fragility fractures will occur. The purpose of this review is to evaluate pregnancy and lactation, two recurrent conditions in the life of many women, with potential to influence BMD. In addition, we aimed to evaluate if multiple pregnancies and an extended period of lactation are risk factors for osteoporosis and future fragility fractures. The search for relevant publications was done with a Medline search from 1966 onwards, using the search words bone mineral density, bone mass, BMD, pregnancy, lactation, multiparity, multiple pregnancies and fractures. Furthermore, the article should have been published in English. From the articles we found, we extended the search through the link "related manuscript” repeatedly until no new relevant articles were found.

\section{Pregnancy and BMD}

A variety of prospective controlled or non-controlled studies suggest that pregnancy is associated with a loss in BMD (Table 1). In studies with this design the BMD loss during pregnancy has been reported at a magnitude of $2.4 \%$ in the femoral neck in one study including 6 women (3), 3.2\% in the spine and total hip in one study including 10 women (4), 4.9\% in the ultra-distal forearm in one study including 38 women (5), 3.0\% in the spine in one study including 5 women (6), 4.6\% in the spine in one study including 16 women (7) and 9\% in the spine in one study including 14 women (8). The two perhaps most cited studies which oppose the view of BMD loss during pregnancy included 32 women (9) and 10 women (10) 
respectively. In the first study the follow-up time differed in pregnant and non-pregnant women, 475 and 669 days respectively (9), and the risk of making a type II error in the second study must be regarded as high (10). Only the studies by Karlsson et al. (11) and Sowers et al. (9) performed the follow-up measurements close to delivery, 3 days and 15 days after parturition respectively. In other studies the baseline measurements were conducted up to 12 months before conception and the follow-up measurements up to 12 months after delivery, a fact that will inevitably include the influence of lactation in the outcome. Furthermore, only three studies were controlled, and none of the prospective studies adjusted the BMD values for changes in soft tissue composition. Only one cross-sectional study adjusted the BMD values for differences in soft tissue composition when pregnant and non-pregnant women were compared (11). This study found 7.6\% lower lumbar spine BMD and 3.9\% lower total body BMD in just delivered mothers in comparison with 55 age- and gender-matched controls. Thus, it seems as if available data, in conjunction with a recently published large review (12), strongly suggest that pregnancy is associated with a maternal loss of BMD around 5\% (Table 1). Hypothetically this loss would increase the fracture risk by 50\%, if BMD remained at this level after delivery. Available data also suggest that any general interventions have little or no effect on the BMD loss, except perhaps calcium supplement in women with a very low calcium intake, and that heparin treatment in pregnant women may increase the BMD loss.

\section{Pregnancy-related osteoporosis and transient osteoporosis of the hip}

Most women lose a small amount of BMD during pregnancy, but pregnancy-related osteoporosis is a rare complication with unknown incidence (13). Pregnancy-related transient osteoporosis of the hip is another condition that probably reflects the same background, although localised only in the hip $(14,15)$. Published data include mostly case reports, but 
two published cases series exist, including 24 (13) and 35 patients (16) respectively. The diseases usually affect slightly built, primigravid, lactating women, but the disease usually does not recur during subsequent pregnancies. The disease is often diagnosed during the third trimester, but otherwise little is known about the dynamics of the BMD decrement when the disease develops, or about recovery in BMD $(13,16-19)$. Even if the pathogenesis of the disease is unknown, it is usually regarded as benign, since virtually all patients return to normal BMD without treatment 6 to 12 months after weaning. The condition does not leave long-term deficits, except in the women whose period with osteoporosis was complicated by a vertebral, sacrum or hip fracture $(13,16-20)$.

\section{Can supplementation or any other intervention influence BMD during pregnancy}

Nutrition is one of the more important BMD regulatory factors in both the development and the maintenance of BMD. Approximately $90 \%$ of BMD consists of calcium and phosphorus, but other dietary components, such as protein, magnesium, zinc, copper, iron, fluoride, vitamins D, A, C and $\mathrm{K}$ are also included and required for normal bone metabolism. As the amount of calcium is so dominant in the skeleton, this mineral is usually regarded as the most important single nutrient, and is also the most studied nutritional element. The calcium content is vital for skeletal development not only during growth (21), but also in premenopausal (1) and postmenopausal women (22). Calcium functions with a threshold limit so that the calcium intake is relevant up to a threshold intake only, and adding more calcium above this will not improve the BMD (23). Pregnancy confers an extra demand for calcium as the foetus is daily supplied with $50 \mathrm{mg}$ at 20 weeks’ gestation up to $330 \mathrm{mg}$ at 35 weeks’ gestation (24). The mother meets this demand by increasing the concentration of 1,25dihydroxyvitamin (calictriol) while the concentration of parathyroid hormone and calcitonin stays almost unchanged $(24,25)$. As a result, calcium absorption increases in both the gut and 
the kidney. The question then arises - can calcium supplement influence BMD during pregnancy? Most data suggest that calcium supplements in pregnant women with normal or high calcium intake have little or no effect on BMD (10), but there are weak data suggesting that pregnant women with very low calcium intake may benefit from calcium supplementation (26). In contrast to other nutritional elements, smoking, caffeine and alcohol exert a negative influence on BMD. If intervention strategies that reduced the intake of these elements could influence the BMD during a pregnancy is debated (27), as if intervention with physical activity could reduce the pregnancy related BMD loss (28).

\section{Lactation and BMD}

A large number of prospective controlled or non-controlled studies suggest that lactation is associated with a loss in $\operatorname{BMD}(3,10,29-33)$ (Table 2$)$. With the prospective study design, the BMD loss during six months of lactation has been reported at a magnitude of $6 \%$ in the femoral neck in one study including 10 women (3), 7.5\% in the lumbar spine in one study including 36 women (31), 7.1\% in the ultradistal radius in one study including 40 mothers who breast-fed and 40 age-matched controls (29) and 4\% in the spine in one study including 26 lactating women and 8 non-lactating controls (32). The findings are supported in a variety of studies, suggesting a 3 to $6 \%$ loss in BMD, most pronounced in the axial skeleton, with 3 to 6 months of lactation (34-38) (Table 2). The finding of a dose response relationship, so that a longer period of lactation is associated with larger BMD loss and shorter periods of lactation with lower BMD loss, strengthens the view that lactation does influence BMD loss $(5,8,36)$. So far the only study which has provided BMD values adjusted for changes in soft tissue composition during the lactation period supports the previously described notions, reporting a loss in BMD of $4.1 \%$ in the lumbar spine and $2.0 \%$ in the femoral neck with 5 months' lactation in 65 women compared with 55 non-lactating mothers (Figure 1) [9]. Lactation 
beyond 6 months did not decrease BMD further in this study, and moreover, 12 months after delivery, the BMD was completely recovered in the lumbar spine and partially in the femoral neck. Also, a recently published review supports the suggestion that a reduction in BMD occurs with lactation, but that this reduction is reversible after weaning (12). This is in agreement with virtually all studies following BMD after weaning, reporting that BMD is restored 6 to 18 months post weaning (34-38). It has also been proposed that this recovery cannot occur in women with closely spaced pregnancies, and so is a risk factor for osteoporosis later in life, due to additive periods with BMD loss in quick succession (31). However, published studies consistently show that women with many closely spaced pregnancies and with extended lactation do not risk failure of bone recovery to pre-lactation levels $(39,40)$. There exist also data that suggest that the small amounts of gestagen in the progesterone-only pill would appear to protect against this loss (41). The mechanism of this loss in bone mineral density and the potentially bone protective effects of gestagens require further study.

\section{Can supplementation or any other intervention influence BMD during lactation}

Calcium intake is of importance during lactation. An increased maternal demand for calcium occurs during lactation, as $200 \mathrm{mg}$ of calcium is transferred daily in the mother's milk to the infant during full breast-feeding. This leads to a total calcium transfer via the breast milk during one lactation period of 3 to 6 months, which is greater than the calcium transferred across the placenta during pregnancy (24). As maternal absorption and excretion of calcium are altered postpartum, so that the calcium absorption and urinary calcium excretion return to pre-pregnancy levels shortly after delivery $(8,10,42)$, there could hypothetically be a shortage of calcium for the skeleton which would hypothetically if anything lead to decreased BMD. The clinically relevant question then arises - is the calcium and vitamin D intake of the 
mother of importance for BMD, and could a supplement of extra calcium and vitamin D affect BMD? Randomised, controlled intervention studies with calcium supplement, given to lactating women with high and low calcium intake, have shown no effects on bone turnover markers $(10,24,25,42)$. The studies using the BMD as end point suggest that extra calcium has little or no positive effect on BMD loss during lactation, and any effect is usually described as transient with no long-term benefits (42-44). Additionally, the few studies which report a small effect of calcium postpartum have usually found the same beneficial effect in non-lactating mothers $(10,29,30)$, suggesting that calcium supplement does not influence the specific lactation-induced BMD loss. This view is further strengthened by one study reporting that also breastfeeding women with low calcium intake did not benefit from calcium supplement (30). Furthermore, no studies indicate that vitamin D requirements are greater in lactating than non-lactating women (45). If intervention strategies that reduced the intake of smoking, caffeine and alcohol could influence the BMD during lactation is debated (27), as if intervention with physical activity could reduce the BMD loss related to lactation (28).

\section{The long-term effects of pregnancies and lactation on BMD}

Perhaps the most clinically relevant question is whether the pregnancy- and lactation-related loss in BMD is reversible, or if there is an association between parity and low BMD and increased fracture risk. If so, pregnancy and lactation could be used as a risk factor for future fractures, when prophylactic treatment strategies against fragility fractures should be discussed. A variety of observational and case control studies suggest that women with a history of multiple pregnancies and a long period of lactation have no different or higher BMD than their sisters with few or no children (Table 3). In 39 pre-menopausal women with a minimum of four pregnancies, after adjustment for differences in soft tissue composition, BMD was no lower than in 58 age-matched controls with a maximum of 2 pregnancies (11). 
Furthermore, the duration of lactation was not correlated with BMD in this study. The notion that the number of pregnancies is not correlated with BMD in elderly women has also been reported in 465 pre- and 713 post-menopausal Japanese women (46), in 70-year-old Swedish women (47) and in a recently published review including 23 different citations (12).

In contrast, other studies have reported a 3-5\% higher BMD in women with a history of one or several children in comparison with nulliparous women. Women with a history of two deliveries had higher BMD than women with no deliveries, at a magnitude of $3 \%$ in the total body, $8 \%$ in the femoral neck and $4 \%$ in the leg in one study including 1855 post-menopausal women (48), similar to the conclusions drawn in one study including 1652 peri- and postmenopausal Norwegian women (49), in one including 580 English women aged 45-61 years (50), in one including 3126 Finnish women aged 47-56 years (51), in one including 825 English women aged 41-76 years (52), in one including 217 white American women aged 22-54 years (53) and in one including Italian women aged 22-54 years (54) (Table 3). This association is further strengthened when studies report a dose response relationship, so that the lowest BMD was found in nulliparous women, intermediate values in primiparae and the highest value in women with two or more children (52). These finding are confusing as both a pregnancy and a period of lactation are followed by a BMD loss. Apparently, these findings are of minor clinical importance in the long term. It seems as if other factors overshadowed this loss so that mothers with many children and a long period of lactation have similar or higher BMD than their peers who have not given birth (Table 3). Today we can only speculate as regards the causality, but changes in lifestyle associated with having a large family seem most likely to account for the outcome. Another possible explanation is that the finding may be due to shared genetic factors, so that women with high BMD are also prone to have many children. 


\section{The long-term effects of pregnancies and lactation on fracture risk}

There are observational and case control studies which evaluate the fracture risk in relation to pregnancies and lactation. These studies suggest that women with a history of multiple pregnancies and a long period of lactation have no different or lower fracture risk than their peers with no children (Figure 2). In 917 women the incidence of hip and forearm fractures was not higher among those who had given birth to four or more children than in women who had not given birth (55). Furthermore, women who had breast-fed for more than two years did not have a higher fracture risk than women who had never breast-fed (55). The conclusion that women with multiple pregnancies do not differ in fracture rate from nulliparous women has been supported in one study including 70-year-old Swedish women (47), in one including Australian women (56), in the Study of Osteoporotic Fracture (SOF), an prospective observational study including 9704 American women over 65 years of age $(1,57)$, in the Mediterranean Osteoporosis study (MEDOS), a cross-sectional study including 2086 women from 14 centres in six countries in Southern Europe with a hip fracture and 3532 nonfractured controls (58) or in the European Vertebral Osteoporosis Study (EVOS), a longitudinal study including 6646 women aged 50-79 years (59).

In contrast, the fracture risk was reported to be only half in women with two or more deliveries in comparison with nulliparous women in one study including 1855 postmenopausal women (48); a 6\% lower fracture risk was found in parous than in nulliparous women in the prospective Dubbo Epidemiological Osteoporosis Study (56); a 10\% lower hip fracture risk per born child (5\% after adjustment for body mass index) was reported in one study including 1328 post-menopausal Swedish women aged 50-81 years with a hip fracture and 3312 matched controls (60); live birth was associated with a 35\% lower hip fracture risk 
in women with children compared to women without in one study including 174 cases and 74 matched controls aged 54 years and over (61). Furthermore, an association between lower hip fracture risk and having one or more children has also been reported in the Leisure World Study, a seven-year prospective study of 8600 post-menopausal women (62), in the EPIDOS study, a 3.6 year prospective study of 7590 women (63), in the SOF study (64) and in a Danish twin study including 3057 twins aged 66-99 years followed for a total of 29112 person-years (65). It seems as if most studies suggest that there is no relationship or an inverse relationship between parity and fracture risk and that there is no association between lactation and fracture risk (Figure 2). When fracture is used as the end point we achieve stronger data than when using a surrogate end point like BMD, when trying to evaluate the clinical importance of the female reproductive history and the skeleton. In conclusion, then, having many children will probably lead to a lifestyle that, if anything, leads to not only high BMD but also reduced fracture risk. This view is further supported when data infer that the association between parity and reduced hip fracture risk may operate through a different mechanism than is detected by $\operatorname{BMD}(66,67)$. The BMD loss found to be associated with a pregnancy and lactation must be regarded as a finding without clinical relevance, as the deficit recovers after weaning.

In summary, most studies are in agreement with the suggestion that pregnancy and lactation lead to a BMD loss of up to $5 \%$, but that this loss is reversed after weaning. Studies of elderly women who have had multiple pregnancies and a long total duration of lactation conclude that multiparous women have similar or higher BMD, and similar or lower fracture risk than women with no history of pregnancy. The causality for this can not be proven by any existing data, but discrepancies in life style factors probably explain, at least partly, the discrepancies. 


\section{Table legends}

Table 1. Relative changes in bone mineral density (BMD) during pregnancy evaluated in several original studies, presented with first author and publication year, numbers of women included and level of significance when comparing the pre-pregnancy and the post-pregnancy values or when comparing cases with controls.

Table 2. Relative changes in bone mineral density (BMD) during 6 months of lactation evaluated in several original studies, presented with first author and publication year, numbers of women included and level of significance when comparing the first post-pregnancy and the 6 months post-pregnancy values.

Table 3. Relative difference in bone mineral density (BMD) in postmenopausal parous women compared with nulliparous women evaluated in several original studies, presented with first author and publication year, numbers of women included and level of significance when comparing parous and nulliparous women.

\section{Figure legends}

Figure 1. Relative changes in bone mineral density (BMD) during the first year following delivery in women with no breastfeeding and in women with breastfeeding below or above 6 months duration.

Figure 2. Relative risk of sustaining a fracture in postmenopausal parous compared with nulliparous women, presented with first author and publication year, numbers of women included, type of fracture evaluated and numbers of pregnancies included, with 95\% confidence interval. 


\section{References}

1. Cummings SR, Nevitt MC, Browner WS, et al. Risk factors for hip fracture in white women. Study of Osteoporotic Fractures Research Group [see comments]. N Engl J Med 1995; 332:767-73.

2. WHO. Assessment of fracture risk and its application to screening for postmenopausal osteoporosis. WHO Technical Report Series 843, Geneva 1994.

3. Drinkwater BL, Chesnut CH, 3rd. Bone density changes during pregnancy and lactation in active women: a longitudinal study. Bone Miner 1991; 14:153-60.

4. Black AJ, Topping J, Durham B, Farquharson RG, Fraser WD. A detailed assessment of alterations in bone turnover, calcium homeostasis, and bone density in normal pregnancy. J Bone Miner Res 2000; 15:557-63.

5. More C, Bettembuk P, Bhattoa HP, Balogh A. The effects of pregnancy and lactation on bone mineral density. Osteoporos Int 2001; 12:732-7.

6. Holmberg-Marttila D, Sievanen H, Tuimala R. Changes in bone mineral density during pregnancy and postpartum: prospective data on five women. Osteoporos Int 1999; 10:41-6.

7. Naylor KE, Iqbal P, Fledelius C, Fraser RB, Eastell R. The effect of pregnancy on bone density and bone turnover. J Bone Miner Res 2000; 15:129-37.

8. Ritchie LD, Fung EB, Halloran BP, et al. A longitudinal study of calcium homeostasis during human pregnancy and lactation and after resumption of menses. Am J Clin Nutr 1998; 67:693-701.

9. Sowers M, Crutchfield M, Jannausch M, Updike S, Corton G. A prospective evaluation of bone mineral change in pregnancy. Obstet Gynecol 1991; 77:841-5. 
10. Cross NA, Hillman LS, Allen SH, Krause GF, Vieira NE. Calcium homeostasis and bone metabolism during pregnancy, lactation, and postweaning: a longitudinal study. Am J Clin Nutr 1995; 61:514-23.

11. Karlsson C, Obrant KJ, Karlsson M. Pregnancy and lactation confer reversible bone loss in humans. Osteoporos Int 2001; 12:828-34.

12. Ensom MH, Liu PY, Stephenson MD. Effect of pregnancy on bone mineral density in healthy women. Obstet Gynecol Surv 2002; 57:99-111.

13. Smith R, Athanasou NA, Ostlere SJ, Vipond SE. Pregnancy-associated osteoporosis. Qjm 1995; 88:865-78.

14. Boissonnault WG, Boissonnault JS. Transient osteoporosis of the hip associated with pregnancy. J Orthop Sports Phys Ther 2001; 31:359-65; discussion 366-7.

15. Uematsu N, Nakayama Y, Shirai Y, Tamai K, Hashiguchi H, Banzai Y. Transient osteoporosis of the hip during pregnancy. J Nippon Med Sch 2000; 67:459-63.

16. Dunne F, Walters B, Marshall T, Heath DA. Pregnancy associated osteoporosis. Clin Endocrinol (Oxf) 1993; 39:487-90.

17. Liel Y, Atar D, Ohana N. Pregnancy-associated osteoporosis: preliminary densitometric evidence of extremely rapid recovery of bone mineral density. South Med J 1998; 91:33-5.

18. Anai T, Tomiyasu T, Arima K, Miyakawa I. Pregnancy-associated osteoporosis with elevated levels of circulating parathyroid hormone-related protein: a report of two cases. J Obstet Gynaecol Res 1999; 25:63-7.

19. Tran HA, Petrovsky N. Pregnancy-associated osteoporosis with hypercalcaemia. Intern Med J 2002; 32:481-5. 
20. Breuil V, Brocq O, Euller-Ziegler L, Grimaud A. Insufficiency fracture of the sacrum revealing a pregnancy associated osteoporosis. First case report. Ann Rheum Dis 1997; 56:278-9.

21. Parfitt AM, Villanueva AR, Foldes J, Rao DS. Relations between histologic indices of bone formation: implications for the pathogenesis of spinal osteoporosis. $J$ Bone Miner Res 1995; 10:466-73.

22. Andon MB, Lloyd T, Matkovic V. Supplementation trials with calcium citrate malate: evidence in favor of increasing the calcium RDA during childhood and adolescence. $J$ Nutr 1994; 124:1412S-1417S.

23. Matkovic V, Heaney RP. Calcium balance during human growth: evidence for threshold behavior. Am J Clin Nutr 1992; 55:992-6.

24. Prentice A. Calcium in pregnancy and lactation. Annu Rev Nutr 2000; 20:249-72.

25. Prentice A. Maternal calcium metabolism and bone mineral status. Am J Clin Nutr 2000; 71:1312S-6S.

26. Raman L, Rajalakshmi K, Krishnamachari KA, Sastry JG. Effect of calcium supplementation to undernourished mothers during pregnancy on the bone density of the bone density of the neonates. Am J Clin Nutr 1978; 31:466-9.

27. Ilich JZ, Kerstetter JE. Nutrition in bone health revisited: a story beyond calcium. $J$ Am Coll Nutr 2000; 19:715-37.

28. Karlsson M, Bass S, Seeman E. The evidence that exercise during growth or adulthood reduces the risk of fragility fractures is weak. Best Pract Res Clin Rheumatol 2001; 15:429-50.

29. Kent GN, Price RI, Gutteridge DH, et al. Human lactation: forearm trabecular bone loss, increased bone turnover, and renal conservation of calcium and inorganic 
phosphate with recovery of bone mass following weaning. J Bone Miner Res 1990; 5:361-9.

30. Prentice A, Jarjou LM, Cole TJ, Stirling DM, Dibba B, Fairweather-Tait S. Calcium requirements of lactating Gambian mothers: effects of a calcium supplement on breast-milk calcium concentration, maternal bone mineral content, and urinary calcium excretion. Am J Clin Nutr 1995; 62:58-67.

31. Affinito P, Tommaselli GA, di Carlo C, Guida F, Nappi C. Changes in bone mineral density and calcium metabolism in breastfeeding women: a one year follow-up study. $J$ Clin Endocrinol Metab 1996; 81:2314-8.

32. Krebs NF, Reidinger CJ, Robertson AD, Brenner M. Bone mineral density changes during lactation: maternal, dietary, and biochemical correlates. Am J Clin Nutr 1997; 65:1738-46.

33. Kent GN, Price RI, Gutteridge DH, et al. Effect of pregnancy and lactation on maternal bone mass and calcium metabolism. Osteoporos Int 1993; 3 Suppl 1:44-7.

34. Kolthoff N, Eiken P, Kristensen B, Nielsen SP. Bone mineral changes during pregnancy and lactation: a longitudinal cohort study. Clin Sci (Lond) 1998; 94:405-12.

35. Lopez JM, Gonzalez G, Reyes V, Campino C, Diaz S. Bone turnover and density in healthy women during breastfeeding and after weaning. Osteoporos Int 1996; 6:153-9.

36. Laskey MA, Prentice A. Bone mineral changes during and after lactation. Obstet Gynecol 1999; 94:608-15.

37. Sowers M, Corton G, Shapiro B, et al. Changes in bone density with lactation. Jama 1993; 269:3130-5.

38. Matsumoto I, Kosha S, Noguchi S, et al. Changes of bone mineral density in pregnant and postpartum women. J Obstet Gynaecol 1995; 21:419-25. 
39. Sowers M, Randolph J, Shapiro B, Jannausch M. A prospective study of bone density and pregnancy after an extended period of lactation with bone loss. Obstet Gynecol 1995; 85:285-9.

40. Laskey MA, Prentice A. Effect of pregnancy on recovery of lactational bone loss. Lancet 1997; 349:1518-9.

41. Caird LE, Reid-Thomas V, Hannan WJ, Gow S, Glasier AF. Oral progestogen-only contraception may protect against loss of bone mass in breast-feeding women. Clin Endocrinol (Oxf) 1994; 41:739-45.

42. Kalkwarf HJ, Specker BL. Bone mineral changes during pregnancy and lactation. Endocrine 2002; 17:49-53.

43. Polatti F, Capuzzo E, Viazzo F, Colleoni R, Klersy C. Bone mineral changes during and after lactation. Obstet Gynecol 1999; 94:52-6.

44. Kalkwarf HJ, Specker BL, Bianchi DC, Ranz J, Ho M. The effect of calcium supplementation on bone density during lactation and after weaning. $N$ Engl J Med 1997; 337:523-8.

45. Specker BL. Do North American women need supplemental vitamin D during pregnancy or lactation? Am J Clin Nutr 1994; 59:484S-490S; discussion 490S-491S.

46. Kojima N, Douchi T, Kosha S, Nagata Y. Cross-sectional study of the effects of parturition and lactation on bone mineral density later in life. Maturitas 2002; 41:203-9.

47. Johansson C, Mellstrom D, Milsom I. Reproductive factors as predictors of bone density and fractures in women at the age of 70. Maturitas 1993; 17:39-50.

48. Cure-Cure C, Cure-Ramirez P, Teran E, Lopez-Jaramillo P. Bone-mass peak in multiparity and reduced risk of bone-fractures in menopause. Int J Gynaecol Obstet 2002; 76:285-91. 
49. Forsmo S, Schei B, Langhammer A, Forsen L. How do reproductive and lifestyle factors influence bone density in distal and ultradistal radius of early postmenopausal women? The Nord-Trondelag Health Survey, Norway. Osteoporos Int 2001; 12:222-9.

50. Grainge MJ, Coupland CA, Cliffe SJ, Chilvers CE, Hosking DJ. Reproductive, menstrual and menopausal factors: which are associated with bone mineral density in early postmenopausal women? Osteoporos Int 2001; 12:777-87.

51. Tuppurainen M, Kroger H, Saarikoski S, Honkanen R, Alhava E. The effect of gynecological risk factors on lumbar and femoral bone mineral density in peri- and postmenopausal women. Maturitas 1995; 21:137-45.

52. Murphy S, Khaw KT, May H, Compston JE. Parity and bone mineral density in middle-aged women. Osteoporos Int 1994; 4:162-6.

53. Sowers MR, Clark MK, Hollis B, Wallace RB, Jannausch M. Radial bone mineral density in pre- and perimenopausal women: a prospective study of rates and risk factors for loss. J Bone Miner Res 1992; 7:647-57.

54. Mariconda M, Pavia M, Colonna A, et al. Appendicular bone density, biochemical markers of bone turnover and lifestyle factors in female teachers of Southern Italy. Eur J Epidemiol 1997; 13:909-17.

55. Alderman BW, Weiss NS, Daling JR, Ure CL, Ballard JH. Reproductive history and postmenopausal risk of hip and forearm fracture. Am J Epidemiol 1986; 124:262-7.

56. Nguyen TV, Jones G, Sambrook PN, White CP, Kelly PJ, Eisman JA. Effects of estrogen exposure and reproductive factors on bone mineral density and osteoporotic fractures. J Clin Endocrinol Metab 1995; 80:2709-14.

57. Black DM, Cooper C. Epidemiology of fractures and assessment of fracture risk. Clin Lab Med 2000; 20:439-53. 
58. Johnell O, Gullberg B, Kanis JA, et al. Risk factors for hip fracture in European women: the MEDOS Study. Mediterranean Osteoporosis Study. J Bone Miner Res 1995; 10:1802-15.

59. O'Neill TW, Silman AJ, Naves Diaz M, Cooper C, Kanis J, Felsenberg D. Influence of hormonal and reproductive factors on the risk of vertebral deformity in European women. European Vertebral Osteoporosis Study Group. Osteoporos Int 1997; 7:72-8.

60. Michaelsson K, Baron JA, Farahmand BY, Ljunghall S. Influence of parity and lactation on hip fracture risk. Am J Epidemiol 2001; 153:1166-72.

61. Hoffman S, Grisso JA, Kelsey JL, Gammon MD, O'Brien LA. Parity, lactation and hip fracture. Osteoporos Int 1993; 3:171-6.

62. Paganini-Hill A, Chao A, Ross RK, Henderson BE. Exercise and other factors in the prevention of hip fracture: the Leisure World study. Epidemiology 1991; 2:16-25.

63. Schott AM, Cormier C, Hans D, et al. How hip and whole-body bone mineral density predict hip fracture in elderly women: the EPIDOS Prospective Study. Osteoporos Int 1998; 8:247-54.

64. Hillier TA, Rizzo JH, Pedula KL, et al. Nulliparity and fracture risk in older women: the study of osteoporotic fractures. J Bone Miner Res 2003; 18:893-9.

65. Petersen HC, Jeune B, Vaupel JW, Christensen K. Reproduction life history and hip fractures. Ann Epidemiol 2002; 12:257-63.

66. Hillier TA, Rizzo JH, Pedula KL, et al. Nulliparity and osteporotic fracture risk. $J$ Bone Miner Res 2004; 19:339.

67. Robbins J, Schott A, Meunier P. Nulliparity and osteoporotic fracture risk. J Bone Miner Res 2004; 19:338; author reply 339. 


\section{Bone Mass Changes During Pregnancy}
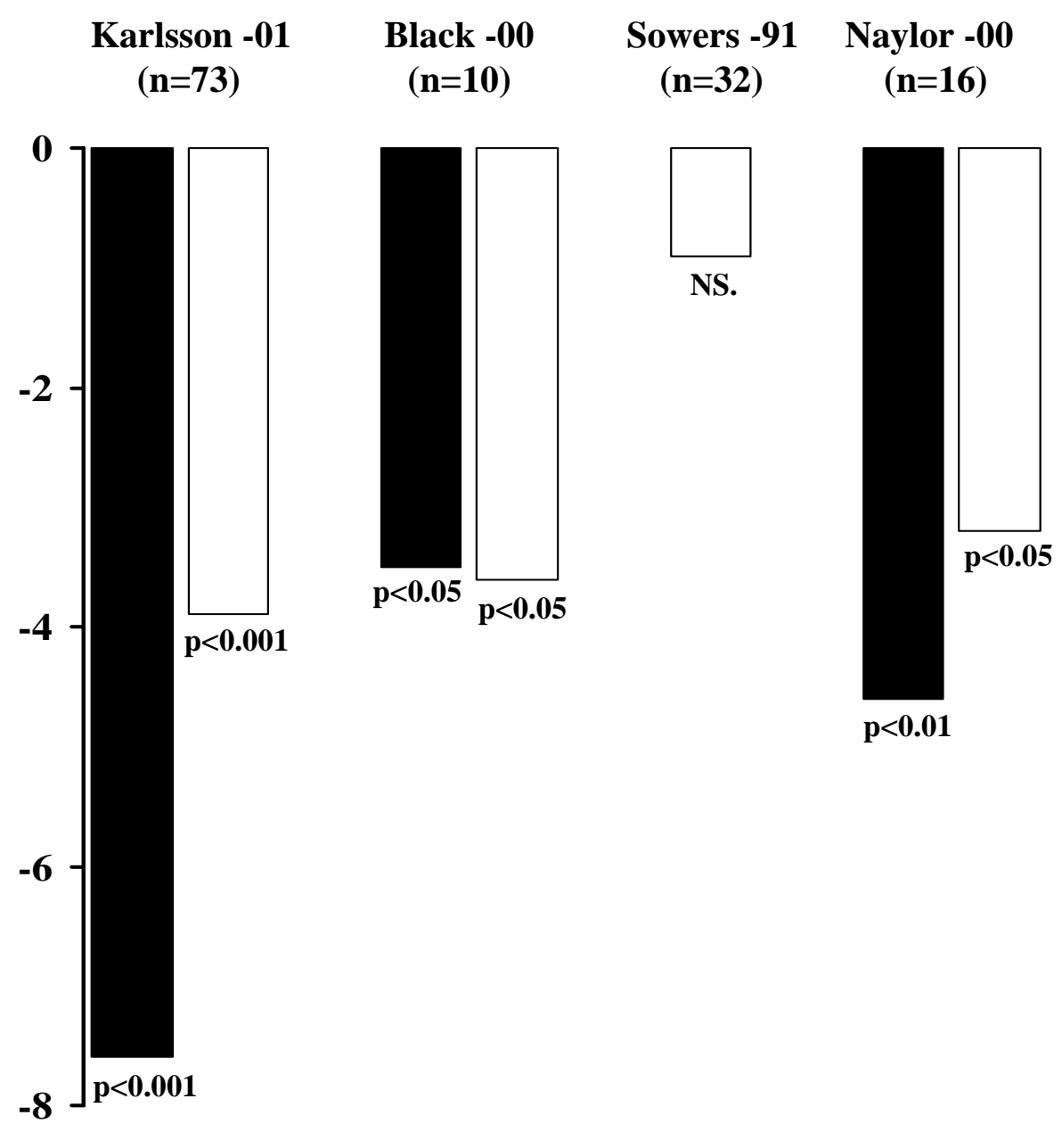

Holmberg- More -01

Mattila -99

$\%$ $(n=5)$
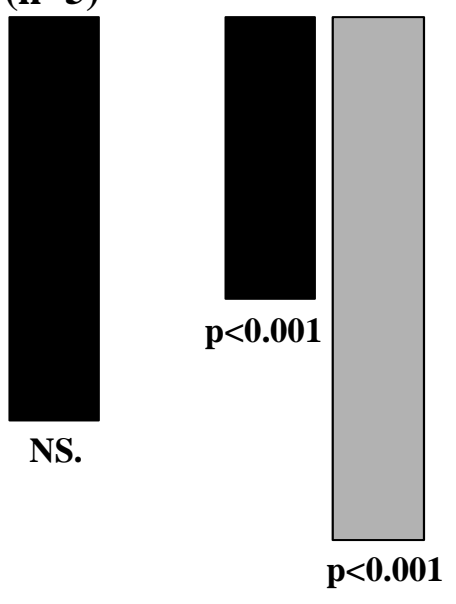

Richie -98 Drinkwater -91

$(n=14)$

$(\mathbf{n}=6)$
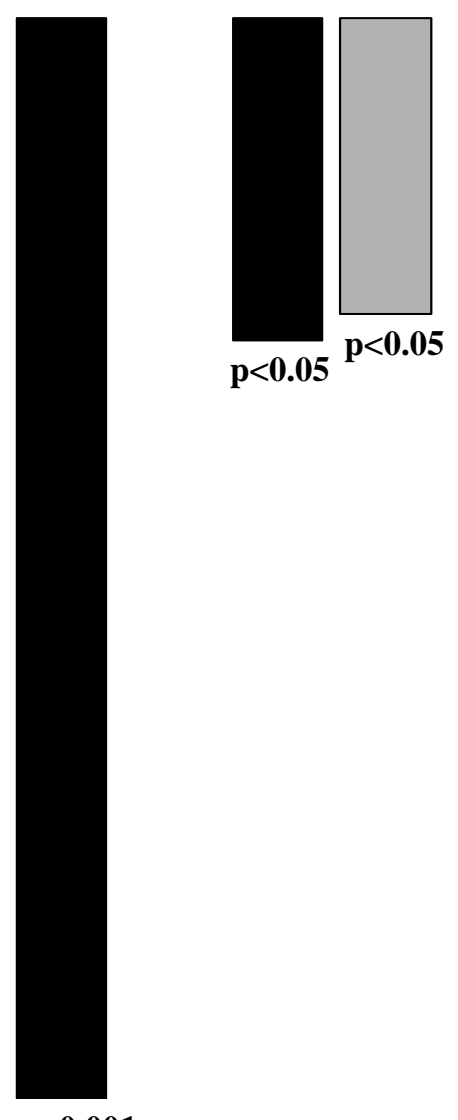

Spine

Hip/Pelvis

Distal Radius 


\section{Bone Mass Changes During Six Months Lactation}
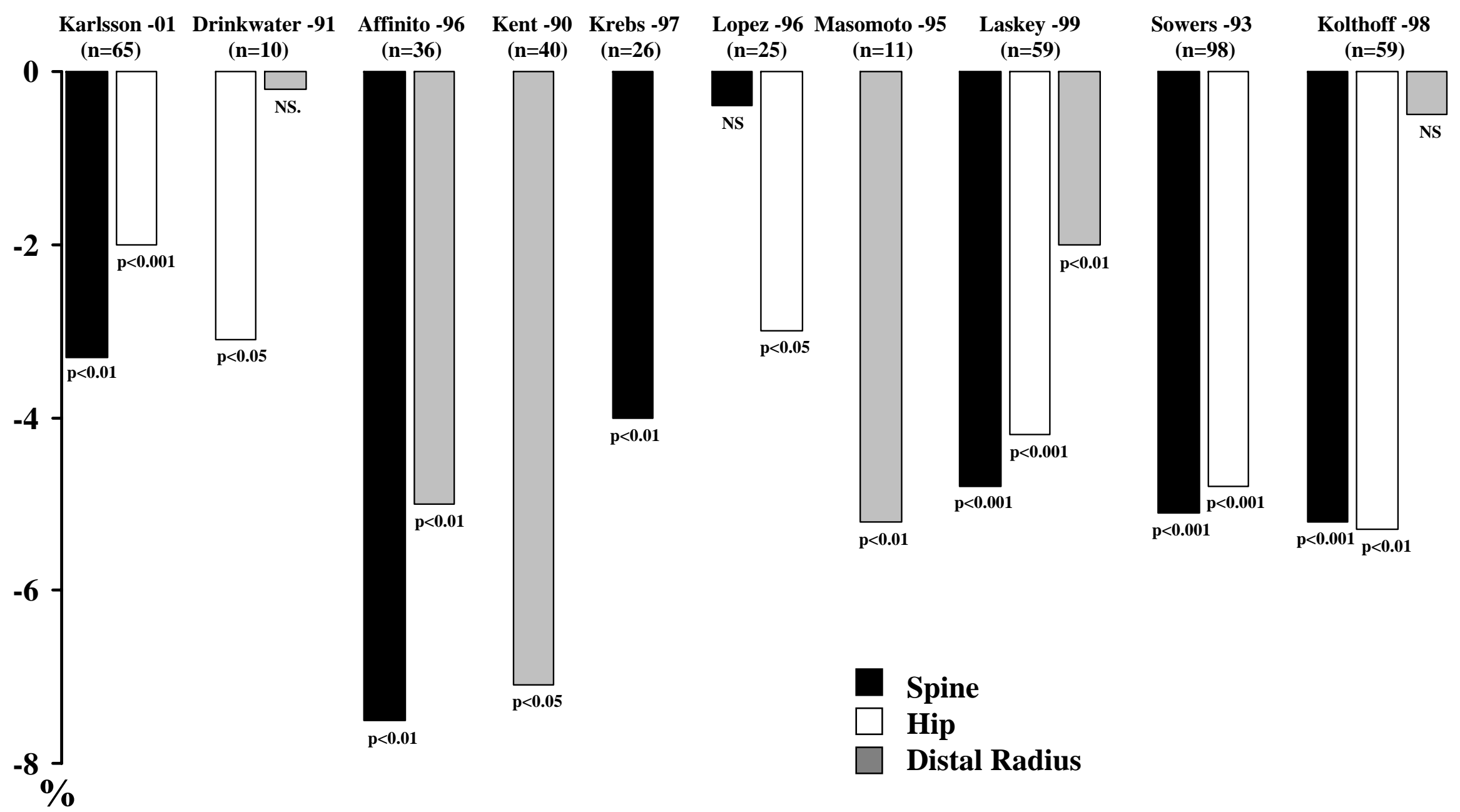

Spine

$\square$ Hip

$\square$ Distal Radius 

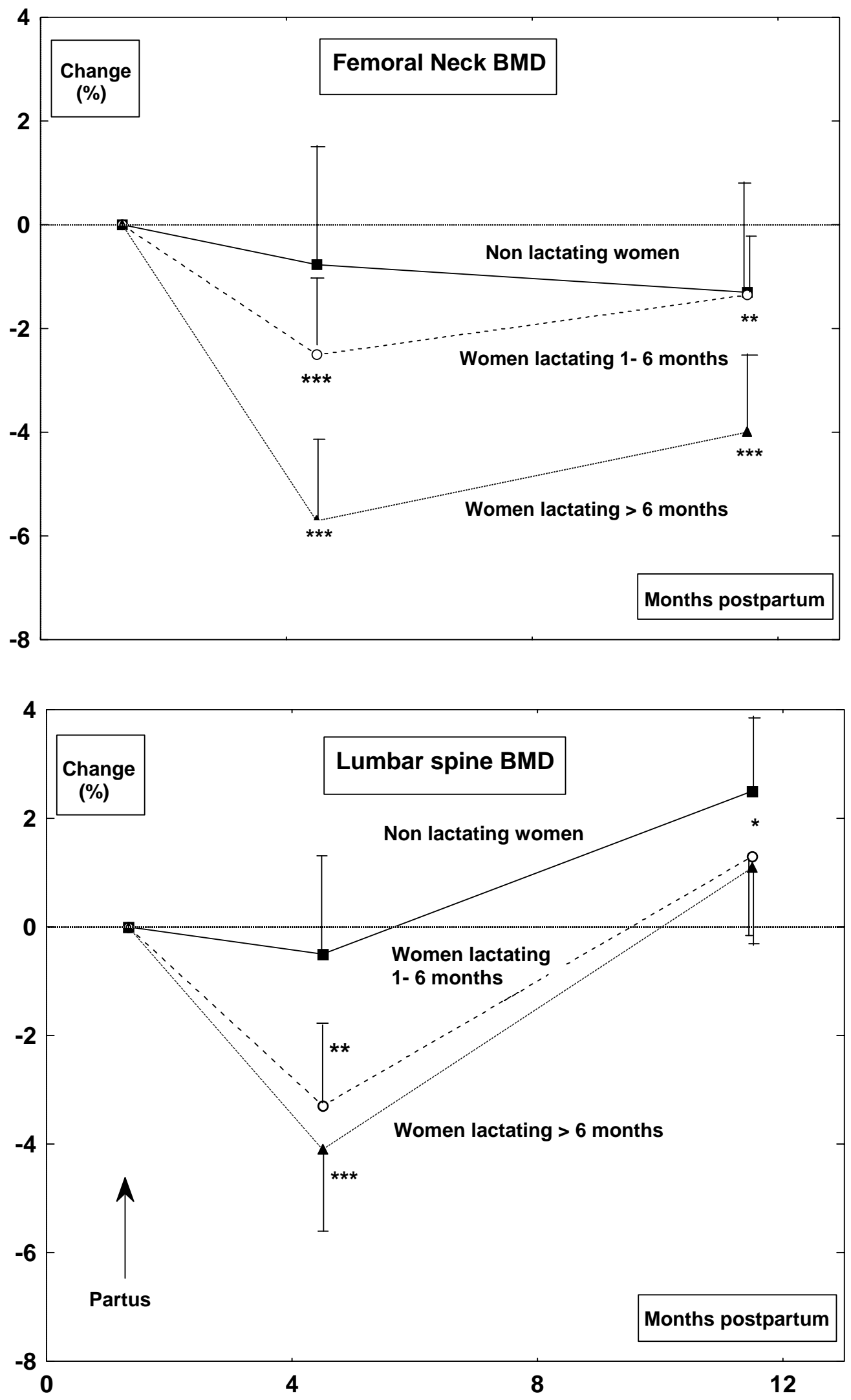


\section{Bone Mass in Parous and Nulliparous Women}
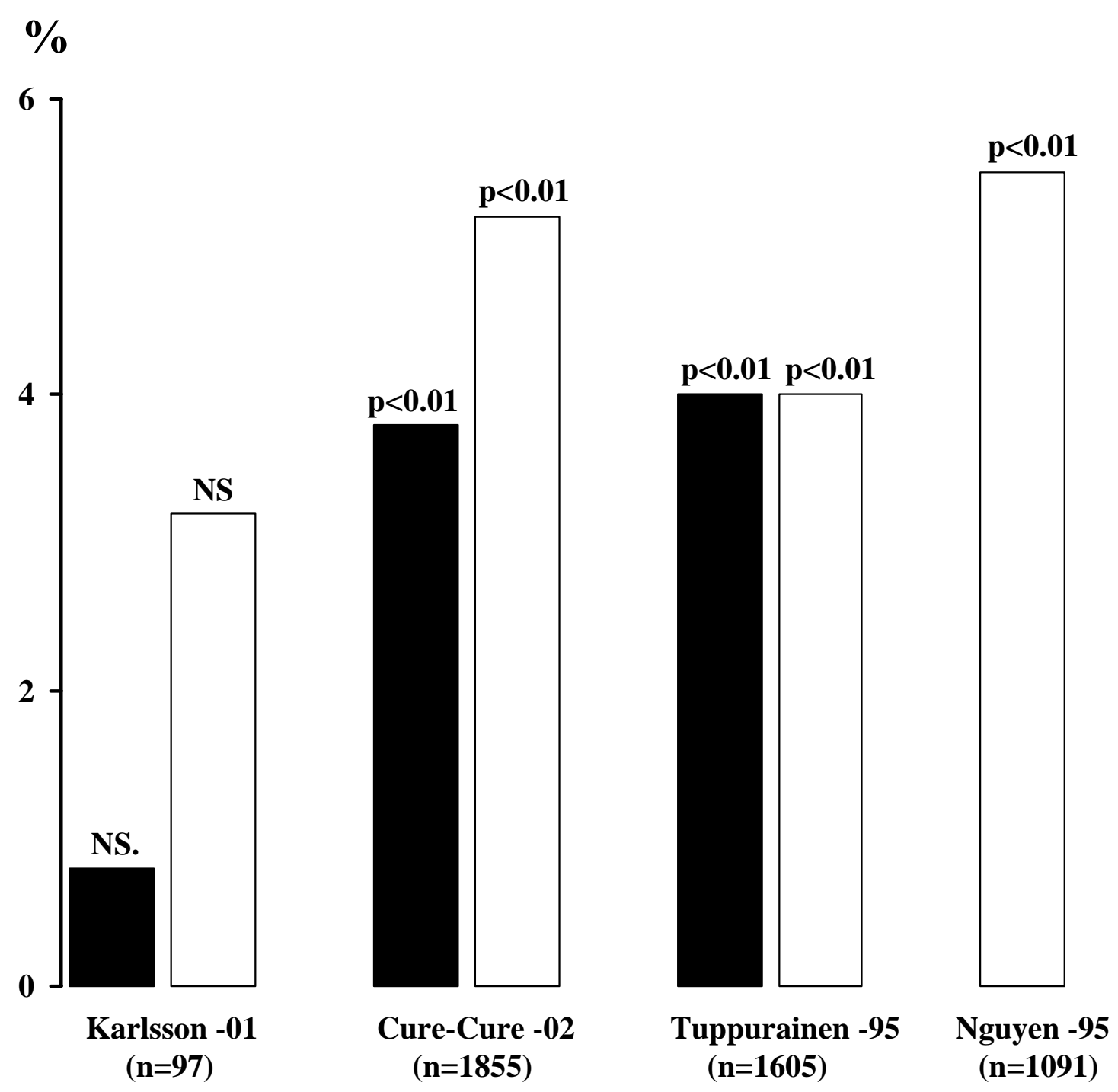

- Spine

$\square$ Hip

Distal Radius

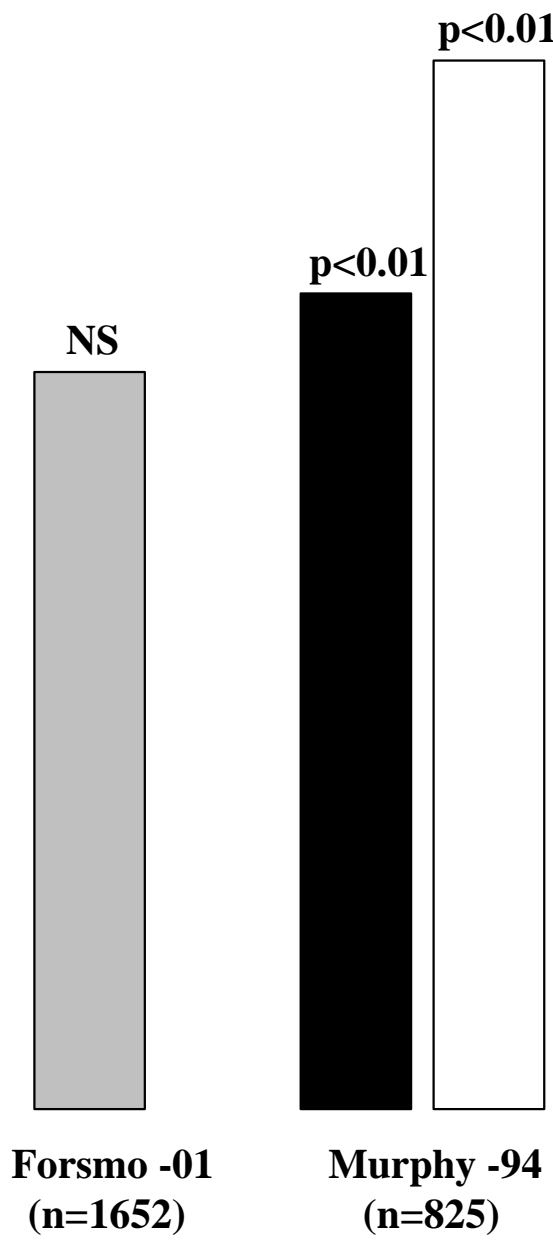




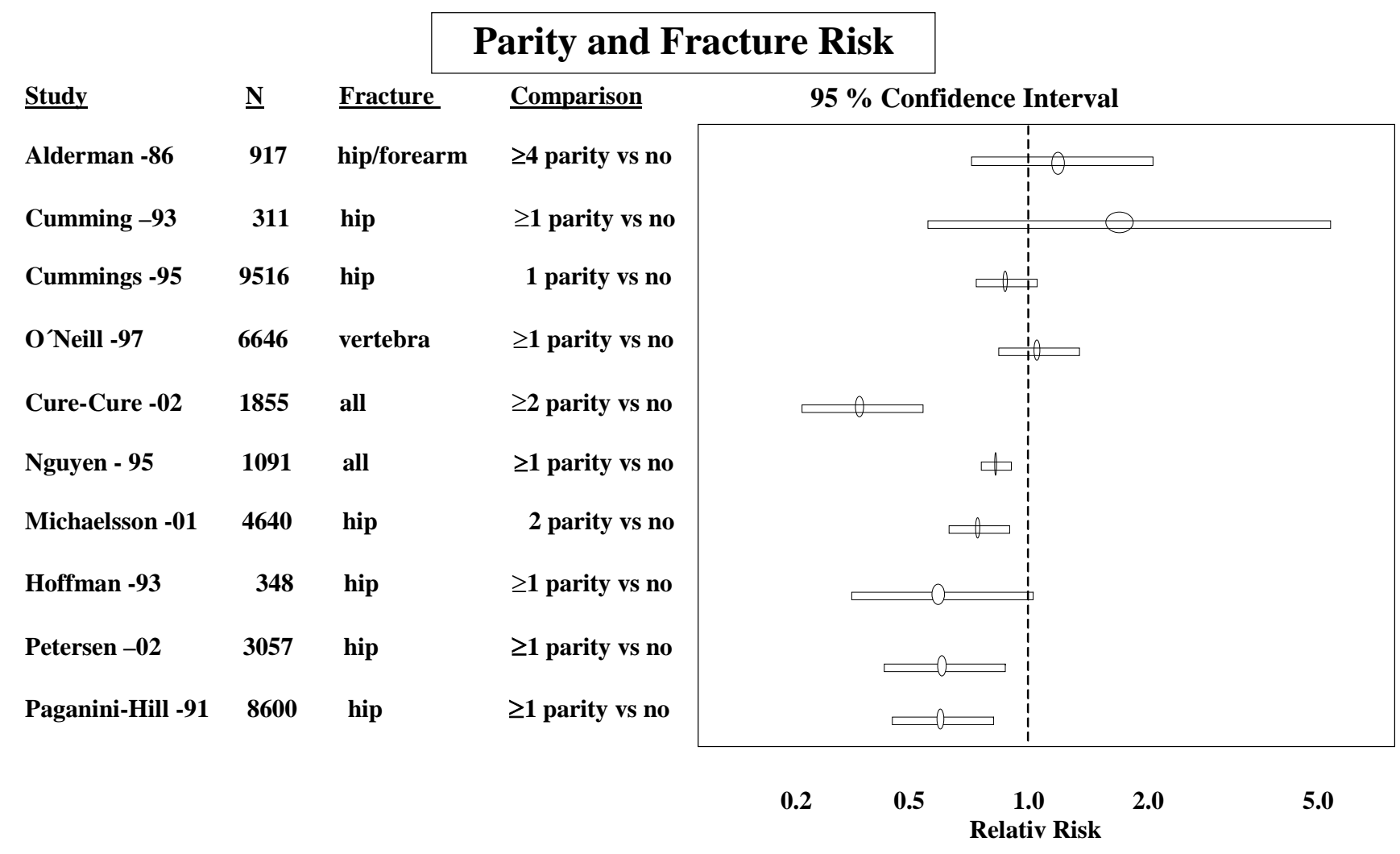

